\title{
MODELLING AND SIMULATION OF A CONVEYOR BELT SYSTEM FOR OPTIMAL PRODUCTIVITY
}

\author{
Ganiyat Salawu \\ Department of Mechanical Engineering \\ University of KwaZulu-Natal, Durban, South Africa \\ Glen Bright \\ Department of Mechanical Engineering \\ University of KwaZulu-Natal, Durban, South Africa \\ Chiemela Onunka \\ Department of Mechanical Engineering \\ Mangosuthu University of Technology, South Africa
}

\begin{abstract}
The productivity level in an advanced manufacturing environment can be improved by proper design of mechanism at the initial stage in the manufacturing system. The aim of this paper is to model and simulate the design parameters of a conveyor system that transport parts from one production stage to another. The approach of model-based design and simulation was used to achieve optimal efficiency of conveyor belt during its operation. Working parameters that can determine the measurable performance of conveyors were studied and presented in a classical model. Outcome from the analysis were simulated using MATLAB software. Simulation results shows that the design parameters used, gave an optimal operating speed at a reduced time of operation.
\end{abstract}

Keywords: Conveyor system; component; Modelling; Simulation; Efficiency.

Cite this Article: Ganiyat Salawu, Glen Bright and Chiemela Onunka, Modelling and Simulation of a Conveyor Belt System for Optimal Productivity. International Journal of Mechanical Engineering and Technology 11(1), 2020, pp. 115-121.

https://iaeme.com/Home/issue/IJMET?Volume $=11 \&$ Issue $=1$

\section{INTRODUCTION}

This work presents a classical model that can be adopted in an early stage of manufacturing when a conveyor belt design is required for optimal productivity. Proper material handling in industries is an important area that requires improvement in order to regulate overall production cost. Higher efficiency of the conveyor belt assists manufacturers to obtain higher productivity during manufacturing and material handling stages [1]. Conveyor belts is 
common in an advanced manufacturing environment for transportation of raw materials from initial stage to finished products stage [2]. A simple diagram of the conveyor belt system is given in Figure 1. The different components of a belt conveyor system are mainly the electric drives, pulleys, idlers, and a long belt. The energy consumption of a conveyor belt can add up to the expenditure in manufacturing industries and lead to an increase in operating cost [3]. The on-going drive among competitors in manufacturing industries requires effective design that can lower the utilization of operating resources [3] [4] [5]. Therefore, a design that can reduce power utilization is required to lower the overall cost of production.

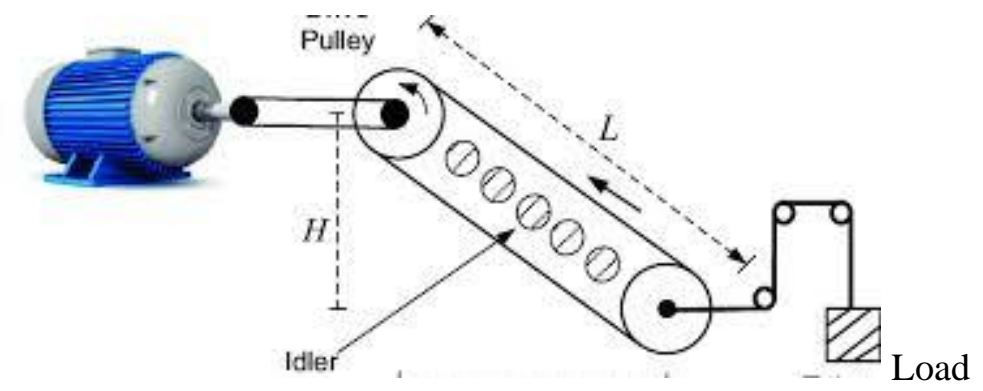

Figure 1: Typical diagram of a conveyor belt system

Previous works has been done to study the conveyor system efficiency using various approach. Shirong and Xiaohua carried out a research to improve the energy efficiency of conveyor belt system by using modelling and optimization approach. The analytical modelling was initiated to describe the stages involved in its operation. Various parameters assumed to represent the conveyor operation were simulated and optimized to achieve the best operating efficiency (Shirong, 2011). In the work of Irfan and Sania, the energy efficiency of conveyor system was studied by considering various factors that contributes to the cost of electricity of a conveyor system. Different stages involved were modelled by considering the driving speed when it was fully loaded, partially loaded and when there was no load on it. This enabled them to come up with a relationship between the speed of the conveyor belt, belt loading dynamic, and rate of power consumed during conveyor system operation [7].

Energy reduction has been a major area of concern to recent researchers. This will assist manufacturers to reduce cost of manufactured parts. An attempt to control energy consumption of a conveyor system was also a success in the work of Halepoto et al. The cost of electricity in electrically and mechanically driven components of conveyor system was evaluated by controlling the multiple drive system of the mechanism. This enable adequate evaluation and integration of some factors that might lead to high consumption rate of electricity [8]. A dynamic model developed was suitable for comparing the behavior of the driving mechanism of a conveyor belt. Outcome from simulation effectively analyzed the relationship between the dynamic behavior of a multiple driven conveyor system and a single conveyor system [9].

Weight is also a design factor to be considered when designing a conveyor system. In [10] [11], a roller belt conveyor system was redesigned for weight reduction. The optimization of an existing roller was carried out whereby the C-channel that serves as the support for the chassis was re-designed, and Modelled using the ANSYS software. The re-designed chassis gave a roller conveyor with minimal weight [11]. The evaluation of materials for the design of conveyor belt requires the selection of a standard design parameters that can be cost effective, durable and can be able to withstand load above its limit [3].

Sustainability is also an important factor to be considered when designing conveyor system. The conveyor system must be able to sustain any environmental factor without affecting its operations. The approach to optimize the design of a conveyor system lead to a 
more effective manufacturing by reducing cost of manufacturing. A suitable design was selected for the conveyor chain. The design adequately reduced the energy consumed during the service condition of the conveyor system [6]. In [12], speed control of conveyor belt can reduce its energy consumption. Effective control and simulation or system analysis produces an optimum acceleration time [12]. The rapid growth of technology required conveyor design that can satisfy transportation of any kind of material. Parameters such as the shaft pitch, number of rollers incorporated were studied to enable the conveyor belt to properly handle glass materials of different sizes [13]. A composite system for a conveyor line speed was designed and modelled. The controller was effective to solve some existing manufacturing problem [14]. Furthermore, an adaptive observer was effectively implemented in estimating some unknown parameters of a conveyor belt system. The model developed gave a reliable output when it was used to measure the angular velocity of a rotor that drives a DC motor as well as the feed rate of the conveyor belt system [15]. Different methods of transporting materials exist in manufacturing industry, but the use of conveyor belt has been one of the most common and efficient means of transporting materials and parts from one manufacturing stage to another [16]

A. The need for proper selection of parameters is a factor that determines its efficiency. In this present study, a conveyor belt system that can operate below and above rated speed was considered. The effect was studied by using notable parameters to generate equations that were solved using engineering equation solver. Outcome were simulated using MATLAB software and optimal values that can give us suitable design parameters were selected and illustrated graphically in graph of Figure 2 and 3.

\section{DESIGN MODEL FOR THE CONVEYOR SYSTEM}

The model considers the design of a conveyor belt mechanism that can operate under varying loads within a reduced operating time. The conveyor belt is assumed to be operating within a speed reduction loss of 5\%. Considering the design parameters and notation, an operating conveyor system with optimal efficiency was developed.

\section{DESIGN CONSIDERATION}

This model considers the application of conveyor belt system that transports materials and goods from one manufacturing stage to the other. During operation, the conveyor belt experiences a tensile effect as a result of the weight of the loads that passes through it. These loads can be categorized into:

- Load due to the conveyed materials $\boldsymbol{L}_{\boldsymbol{c}}(\boldsymbol{k g} / \boldsymbol{m})$

- Load due to the idler that guides the belt movement $\boldsymbol{L}_{\boldsymbol{i}}(\mathbf{k g} / \mathbf{m})$

- Load due to the rotational effect of the belt drives $\boldsymbol{L}_{\boldsymbol{b}}(\mathbf{k g} / \mathbf{m})$

The design of a conveyor belt system must consider proper selection of idler type. The selection considers the optimum weight carrying capacity so as to have a design that will not fail during operation. Equation 1, can be used to calculate for the idler load.

$$
L_{i}=\frac{\text { mass of idlers }\left(m_{i}\right)}{\text { spacing between idlers }(I)}
$$

Also, the load due to the conveyed materials is also part of the factors that would be used when the tensile effect is required to be calculated. It can be expressed as the ratio of the capacity of the conveyor to the speed of the rotating belt as given in equation 2 .

$$
L_{c}=\frac{c_{c}}{v}
$$


The tension of the conveyor belt can be evaluated by considering the friction co-efficient $\boldsymbol{f}$, length and height of the conveyor $(l, H)$, acceleration due to gravity $(g)$, inclination angle $\delta$, and the three loading effects. This can be calculated using the equation below

$$
\boldsymbol{T}_{\boldsymbol{b}}=1.37 \times f \times l \times g \times\left(2 \times L_{i}+2 \times L_{b}+L_{c}\right) \times \cos \delta+\left(H \times g \times L_{c}\right)
$$

Two different power are required during the movement of materials on a conveyor belt. The power that drives the pulley and the minimum power required to drive the electric motor. Equation 4 and 5 was developed for the design calculation of the power required to drive the conveyor belt mechanism. $p_{p}$ represents the power required to drive the pulley and can be calculated using equation 4 , and the minimum power required to drive the electric motor can be obtained using equation 5 .

$$
\begin{gathered}
p_{p}=\frac{T_{b} \times v}{1000}(k w) \\
p_{m}=\frac{p_{p}}{D_{f}}
\end{gathered}
$$

Consequently, the conveyor belt acceleration can be obtained using equation 6 .

$$
A=\frac{\left(B_{t s}-T_{\boldsymbol{b}}\right)}{\left[L \times\left(2 \times L_{i}+2 \times L_{b}+L_{c}\right]\right.}
$$

Furthermore, the operating time can be calculated using

$$
T_{t}=60 \mathrm{~A}
$$

The speed of rotation of pulley was calculated using equation 8 .

$$
V=\frac{\pi D N}{60}
$$

Total motor horse power $H_{p}$ was obtained with the addition of equation (4) and (5). A speed reduction of $5 \%$ was considered to take care of losses.

$$
H_{p}=\left(p_{p}+p_{m}\right) \times 1.05
$$

The motor current can be calculated by considering the total horse power to the ratio of voltage required, efficiency, and the power factor as stated in equation 10 .

$$
\text { Motor current }=\frac{H_{p} \times 746}{\text { voltage } \times 1.73 \times \text { efficiency } \times \text { power factor }}
$$

The tensile stress experienced when the conveyor belt is in the steady state can be obtained using equation 11.

$$
T_{p}=\boldsymbol{T}_{\boldsymbol{b}} \times \boldsymbol{s}_{\boldsymbol{k}}
$$

Consequently, the conveyor belt acceleration can be obtained using equation 12

$$
A=\frac{\left(T_{p}-T_{\boldsymbol{b}}\right)}{\left[L \times\left(2 \times L_{i}+2 \times L_{b}+L_{c}\right]\right.}
$$

\subsection{Selected Notations for the Design}

$T_{b}=$ belt tension

$T_{p}=$ tension in pulley

$f_{x}=$ friction co - efficient

$f_{y}=$ run factor of conveyor

$l=$ lenght of the conveyor $(\mathrm{mm})$ 
$L_{i}=$ idler load $(\mathrm{kg} / \mathrm{m})$

$L_{b}=$ load effect of the belt $(\mathrm{kg} / \mathrm{m})$

$L_{c}=$ load of conveyed material $(\mathrm{kg} / \mathrm{m})$

$H=$ conveyor height $(\mathrm{m})$

$p_{p}=$ power required to drive pulley $(\mathrm{kw})$

$p_{m}=$ power required to drive the electric motor

$v=$ speed of conveyor belt $(\mathrm{m} / \mathrm{s})$

$A=$ conveyor belt acceleration $(\mathrm{m} / \mathrm{secs})^{2}$

$B_{f}=$ belt fracture strenght

$I=$ spacing between idler

$D=$ diameter of driving pulley

$\mathrm{T}=$ Ambient temperature

$N=$ number of revolution per minute

$g=$ acceleration due to gravity $9.8 \mathrm{~m} / \mathrm{secs}$

$\delta=$ angle of inclination of the conveyor (degrees)

$T_{t}=$ Operating time

$s_{k}=$ start - up co - efficient

$c_{c}=$ capacity of conveyor

$c_{r}=$ factor responsible for friction to occur

$m_{i}=$ mass of idler

Using the set of derived equations above, values were assumed for some of the design parameters, and solved using the engineering equation solver (EES). Results obtained is given in Table 1:

Table 1: Design parameters for the conveyor belt

\begin{tabular}{|c|c|}
\hline$L_{b}$ & $17 \mathrm{~kg}$ \\
\hline$c_{c}$ & $400 \mathrm{~kg} / \mathrm{secs}$ \\
\hline $\boldsymbol{f}_{\boldsymbol{x}}$ & 0.02 \\
\hline$f_{y}$ & 0.014 \\
\hline$v$ & $2.4 \mathrm{~m} / \mathrm{Sec}$ \\
\hline$T_{t}$ & $12 \mathrm{secs}$, \\
\hline$D$ & 0.62 \\
\hline$N$ & $75 \mathrm{rev} / \mathrm{min}$ \\
\hline$H$ & $20 \mathrm{~mm}$ \\
\hline$l$ & $240 \mathrm{~mm}$ \\
\hline$L_{i}$ & $18,5 \mathrm{~kg}$ \\
\hline$I$ & $1.4 \mathrm{~mm}$ \\
\hline$\delta$ & $6^{\circ}$ \\
\hline$s_{k}$ & 1.5 \\
\hline$D_{f}$ & 1.0 \\
\hline$c_{r}$ & 14 \\
\hline$c_{v}$ & 0.80 \\
\hline$m_{i}$ & $20 \mathrm{~kg}$ \\
\hline$G$ & 9.81 \\
\hline Current (I) & $700 \mathrm{Amps}$ \\
\hline
\end{tabular}




\section{RESULTS AND DISCUSSION}

The graph of figure 2. Shows the relationship between the operating speed of an electric motor and the operating time of the conveyor belt drive. There is a reduction in the time spent during operation as the driving speed increases. Also, Figure 3, shows the relationship between the power consumption and time of operation, this operating condition is suitable and efficient in an advanced manufacturing environment.

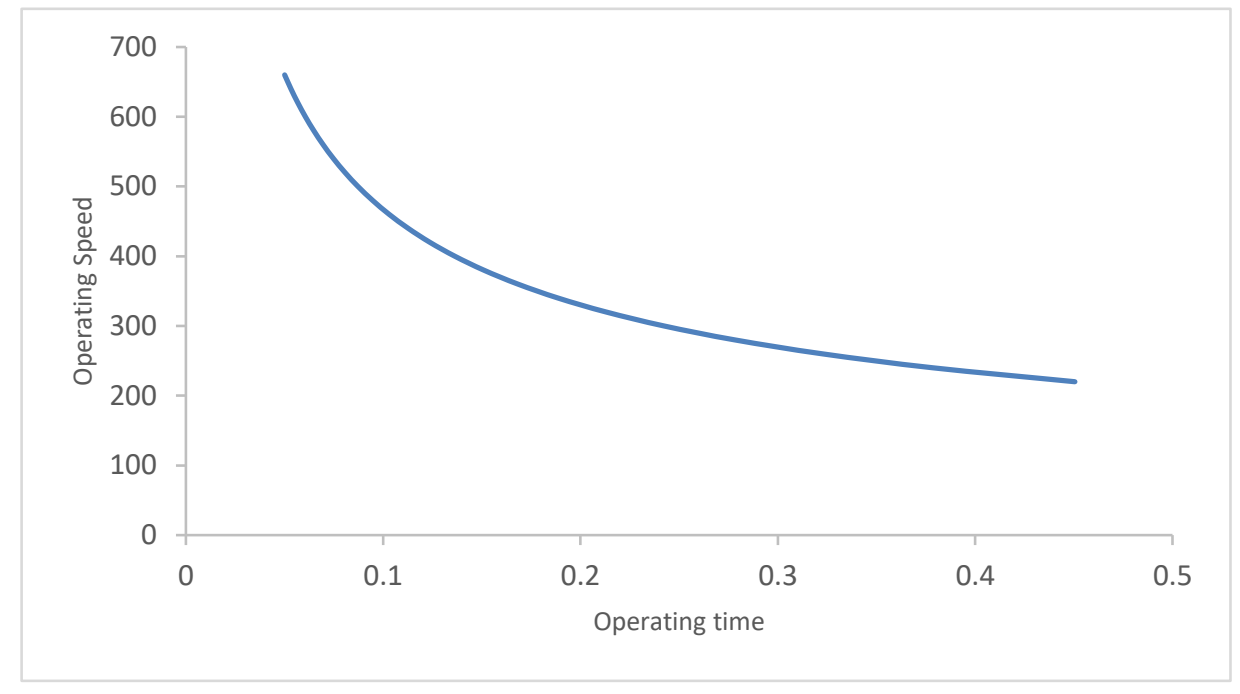

Figure 2. Graph of operating speed against time

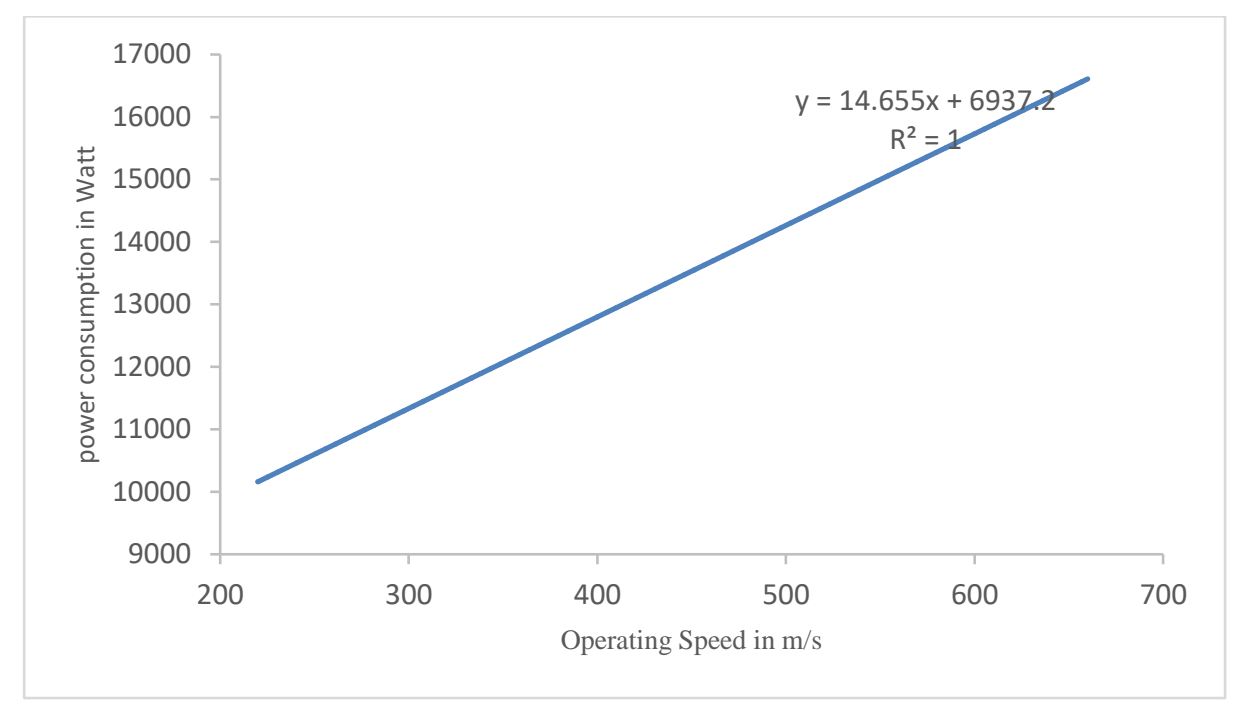

Figure 3. Power consumption VS Operating speed

\section{CONCLUSION}

In previous studies, focus is mainly on how to regulate the conveyor belt with the loads designed for its operation. In this present study, A classical model was designed with some assumed parameters, to study the effect of varying the loads below and above the rated speed of electric motor. Equations were developed using some notations to represent operating parameters of a conveyor belt manufacturing system. MATLAB software was adopted to build simulic mathematical equations and solved using the engineering equation solver (EES). Results obtained were simulated to obtain and select suitable results that gave us optimal design parameters. This enabled proper prediction of optimal operating conditions. For the selected machine, at $390 \mathrm{~m} / \mathrm{secs}$, the optimal operating time is $0.4 \mathrm{secs}$ at a power consumption 
of $12700 \mathrm{~W}$. This proves that the design is suitable when an optimal time for a conveyor speed is required to be selected. Most focus has been on increasing efficiency of conveyor belt system. Thermal analysis of the conveyor belt materials is a good area for further studies.

\section{ACKNOWLEDGMENT}

The financial supports from the TETFUND Nigeria through the federal polytechnic offa, Kwara state Nigeria, (TETFUND/DAST\$D/POLY/OFFA/ASTD/2017/VOL 1) is highly acknowledged.

\section{REFERENCES}

[1] S. S and P. A. Vanamane, "Design, Manufacture and Analysis of Belt Conveyor System used for Cooling of Mould," International Journal of Engineering Research and Applications (IJERA), vol. 2, no. 3, pp. 2162-2167, 2012.

[2] N. D.K, "Design and optimization of roller conveyor system," International journal of science and engineering research, vol. 5, no. 7, 2014.

[3] K. N.S.A, V. R and P. K.W, "Design and Selecting the Proper Conveyor-Belt," International Journal of Advanced Engineering Technology, vol. 4, no. 2, pp. 43-49, 2013.

[4] M. S.M, L. Z and X. X, "A Comparative Study on the Cost-effective Belt Conveyors for Bulk Material Handling," Energy Procedia, vol. 142, p. 2754-2760, 2017.

[5] S. T. \&. M. R, "Design of Belt Conveyor System," International Journal of Science, Engineering and Technology Research (IJSETR), vol. 7, no. 7, pp. 2278 -7798, 2018.

[6] Z. \&. X. X. Shirong, "Modeling and Energy Efficiency Optimization of Belt Conveyors," Applied energy, vol. 88, no. 9, pp. 1-11, 2011.

[7] A. \&. S. K. Irfan, "Modeling of an Integrated Energy Efficient Conveyor System Model using Belt Loading Dynamics," Indian Journal of Science and Technology, vol. 9, no. 47, pp. 1-6, 2016.

[8] [H. I.A, S. M.Z, C. B.S and U. M.A, "Design and Implementation of Intelligent Energy Efficient Conveyor System Model Based on Variable Speed Drive Control," International Journal of Control and Automation. , vol. 9, no. 6, pp. 379-388, 2016.

[9] T. I. S. \&. L. S. A., "The Efficiency Improvement of Belt Conveyor Intermediate Drive Traction Effort," ARPN Journal of Engineering and Applied Sciences, vol. 11, no. 7, pp. 4317-4321, 2016.

[10] V. R.S, S. P, S. C.V, A. M and B. P, "Design and Optimisation of Roller Conveyor System," International Journal of Mechanical Engineering and Technology, vol. 9, no. 4, pp. 116-125, 2018.

[11] P. J, D. D and P. S., "Design and Optimization of Roller in Belt Conveyor," International Journal of Mechanical and Production Engineering, vol. 5, no. 7, pp. 34-37, 2014.

[12] D. H, Y. P and G. L, "Determination of acceleration for belt conveyor speed control in transient operation," International journal of engineering and technology, vol. 8, no. 3, pp. 206-211, 2016.

[13] S. P and K. P, "Design optimization of conveyor rollers arrangement for stable flat pernel display (FPD) glass transfer," Journal of Mechanical Science and Technology, vol. 32, no. 7, pp. 3241-3248, 2018.

[14] U. M. A, E. A.O and E. I.I, "Design and Implementation of Conveyor Line Speed Synchroniser for Industrial Control Applications: A Case Study of Champion's Breweries Plc, Uyo," Nigerian Journal of Technology (NIJOTECH), vol. 35, no. 3, pp. 618-626, 2016.

[15] Y. S. \&. X. X., "Adaptive Parameter Estimation for an Energy Model of Belt Conveyor with Dc Motor," Asian Journal of Control, Vol, vol. 16, no. 4, p. 1122-1132, 2014.

[16] M. B and L. R, "Speed Controlled belt Conveyors: Drives and Mechanical Consideration," Advances in Mechanical and Computer Engineering, vol. 18, no. 11, pp. 51-60, 2018. 